This is an electronic reprint of the original article. This reprint may differ from the original in pagination and typographic detail.

Author(s): Tuononen, Heikki; Suontamo, Reijo; Valkonen, Jussi; Laitinen, Risto; Chivers, Tristram

Title: $\quad$ Conformations and Energetics of Sulfur and Selenium Diimides

Year: $\quad 2003$

Version:

Please cite the original version:

Tuononen, H., Suontamo, R., Valkonen, J., Laitinen, R., \& Chivers, T. (2003).

Conformations and Energetics of Sulfur and Selenium Diimides. Inorganic Chemistry, 42(7), 2447-2454. https://doi.org/10.1021/ic026247+

All material supplied via JYX is protected by copyright and other intellectual property rights, and duplication or sale of all or part of any of the repository collections is not permitted, except that material may be duplicated by you for your research use or educational purposes in electronic or print form. You must obtain permission for any other use. Electronic or print copies may not be offered, whether for sale or otherwise to anyone who is not an authorised user. 


\section{Conformations and Energetics of Sulfur and Selenium Diimides}

Heikki M. Tuononen, ${ }^{\dagger}$ Reijo J. Suontamo, ${ }^{* \dagger}{ }^{\dagger}$ Jussi U. Valkonen, ${ }^{\dagger}$ Risto S. Laitinen, ${ }^{*}{ }^{\ddagger}$ and Tristram Chivers ${ }^{\S}$

Departments of Chemistry, University of Jyväskylä, P.O Box 35, FIN-40014 Jyväskylä, Finland, University of Oulu, P.O Box 3000, FIN-90014 Oulu, Finland, and University of Calgary, 2500 University Drive N.W., Calgary, Alberta, Canada T2N 1N4

\footnotetext{
${ }^{\dagger}$ University of Jyväskylä. Tel.: +358-14-260-2605. Fax.: +358-14-260-2501. E-mail: suontamo@cc.jyu.fi

$\$$ University of Oulu. Tel. +358-8-553-1611. Fax. +358-8-553-1608. E-mail: risto.laitinen@oulu.fi

$\S^{\S}$ University of Calgary.
} 


\begin{abstract}
The geometries and energetics of different conformations of sulfur and selenium diimides $\mathrm{E}(\mathrm{NR})_{2}\left(\mathrm{E}=\mathrm{S}, \mathrm{Se} ; \mathrm{R}=\mathrm{H}, \mathrm{Me},{ }^{\mathrm{t}} \mathrm{Bu}, \mathrm{C}_{6} \mathrm{H}_{3} \mathrm{Me}_{2}-2,6, \mathrm{SiMe}_{3}\right)$ have been studied by using various $a b$ initio and DFT molecular orbital techniques. The syn,syn conformation is found to be most stable for parent $\mathrm{E}(\mathrm{NH})_{2}$ but in general the preferred molecular conformation for substituted chalcogen diimides is syn,anti. In the case of $\mathrm{E}(\mathrm{NH})_{2}$ the present calculations further confirm that syn, syn and syn,anti conformations lie energetically close to each other. From the three different theoretical methods used, B3PW91/6-31G* proved to be the most suitable method for predicting the geometries of chalcogen diimides. The optimized geometrical parameters are in a good agreement with all available experimental data. While qualitative energy ordering of the different conformations is independent of the level of theory, the quantitative energy differences are dependent on the method used. The performance and reliability of higher-level $a b$ initio calculations and DFT methods using large basis sets were tested and compared with experimental information where available. All of the higher-level $a b$ inito methods give very similar results but the use of large basis sets with the B3PW91 method does not increase the reliability of the results. The combination of CCSD(T)/cc-pVDZ with the B3PW91/6-31G* optimized geometries is found to be the method of choice to study energetic properties of chalcogen diimides.
\end{abstract}




\section{Introduction}

The structure and isomerism of sulfur diimides $\mathrm{S}(\mathrm{NR})_{2}$ have attracted considerable interest in view of their utility as ligands in transition metal complexes ${ }^{1-3}$ and as reagents in organic syntheses. ${ }^{4} \mathrm{~S}\left(\mathrm{NSiMe}_{3}\right)_{2}$, in particular, is a convenient source for the NSN fragment in a variety of cyclic and acyclic main-group compounds. ${ }^{5}$

Three different conformations are possible for chalcogen diimides, as shown in Figure 1. Variable temperature NMR spectroscopic studies have indicated that the syn,anti conformation of $\mathrm{S}(\mathrm{NR})_{2}$ is most stable in solution in the case of small organic groups $\left(\mathrm{R}=\mathrm{Me},{ }^{\mathrm{t}} \mathrm{Bu}\right) .{ }^{7} \mathrm{With}$ bulkier organic substituents, small amounts of the anti,anti conformation was inferred to be in equilibrium with the syn,anti conformation. ${ }^{8-10}$ Recently, however, the existence of syn,syn conformations has been reported in the solutions of $\mathrm{S}\left(\mathrm{NC}_{6} \mathrm{H}_{2} \mathrm{Br}_{3}-2,4,6\right)_{2}, \mathrm{~S}\left(\mathrm{NC}_{6} \mathrm{H}_{3} \mathrm{Me}_{2}-2,6\right)_{2}$, and $\mathrm{S}\left(\mathrm{NC}_{6} \mathrm{~F}_{5}\right)_{2}{ }^{11,12}$ Structural determinations of a variety of $\mathrm{S}(\mathrm{NR})_{2}$ molecules by X-ray diffraction in the solid state and electron diffraction in the gas phase have shown the presence of syn,anti and syn,syn conformations depending on the organic substituent $\mathrm{R}^{11-23}$ There are a few semiempirical, ${ }^{11,12,24,25}$ ab initio, ${ }^{26,27}$ and DFT ${ }^{28}$ calculations on sulfur diimides that have established that while syn,anti and syn,syn conformations lie close to each other in energy, the anti,anti conformation lies at a higher relative energy.

In contrast to stable sulfur diimides, selenium diimides $\mathrm{Se}(\mathrm{NR})_{2}$ are thermally unstable. ${ }^{29-}$

32 The only known X-ray structure is that of $N, N^{\prime}$-diadamantyl selenium diimide, which expectedly shows a syn,anti conformation in the solid state. ${ }^{33}$ It has also been inferred from the 
${ }^{1} \mathrm{H}$ and ${ }^{13} \mathrm{C}$ NMR spectra that $\mathrm{Se}\left(\mathrm{N}^{\mathrm{t} B u}\right)_{2}$ exists in solution in the syn,anti conformation. ${ }^{31}$ The analogous tellurium diimides have been observed to undergo a facile [2+2] cycloaddition with the formation of thermally stable dimers $\mathrm{RNTe}(\mu-\mathrm{NR})_{2} \mathrm{TeNR} \cdot{ }^{34-36} \mathrm{~A}$ similar [2+2] cycloaddition has also been observed between $\mathrm{Se}\left(\mathrm{N}^{\mathrm{t} B u}\right)_{2}$ and ${ }^{\mathrm{t}} \mathrm{BuNSeO} .{ }^{37}$ Sandblom et al. ${ }^{28}$ have reported a DFT study of the conformations and dimerization energies of $\mathrm{E}(\mathrm{NMe})_{2}(\mathrm{E}=\mathrm{S}, \mathrm{Se}, \mathrm{Te}) .{ }^{38} \mathrm{These}$ calculations have verified the facile [2+2] cycloaddition of $\mathrm{Te}(\mathrm{NMe})_{2}$. The cycloaddition of methyl sulfur diimide was found to be strongly endothermic and that of methyl selenium diimide was concluded to be approximately thermochemically neutral.

The present $a b$ initio and DFT study was undertaken in order to compare the geometries and energetics of a number of sulfur and selenium diimides at different levels of theory. The scope is to establish the level of reliability in the prediction of geometries and relative energies of different conformations of the monomeric diimides and establish the relevant structural trends. Comparison to experimental information is carried out where possible.

\section{Computational Methods}

All calculations were carried out with the Gaussian 98 program. ${ }^{39}$ Geometries of all different conformations of $\mathrm{E}(\mathrm{NR})_{2}\left(\mathrm{E}=\mathrm{S}, \mathrm{Se} ; \mathrm{R}=\mathrm{H}, \mathrm{Me},{ }^{\mathrm{t}} \mathrm{Bu}, \mathrm{C}_{6} \mathrm{H}_{3} \mathrm{Me}_{2}-2,6, \mathrm{SiMe}_{3}\right)$ were fully optimized at the RHF, ${ }^{40} \mathrm{MP} 2,{ }^{41}$ and B3PW91 ${ }^{42,43}$ levels of theory. The standard 6-31G* basis set was used as implemented in Gaussian 98. The hybrid B3PW91 functional was chosen, since it has been shown to perform well for molecules containing third-row elements. ${ }^{44}$ A standard pruned $(75,302)$ grid was used for B3PW91 optimizations but a denser pruned $(99,590)$ grid was chosen 
for the single point energy calculations in order to minimize inaccuracies arising from the use of numerical integration. The fundamental frequencies were calculated at the RHF and DFT levels of theory in order to assess the nature of stationary points and estimate the zero-point energy (ZPE) corrections.

Two different high-level methods were used to calculate the relative energies of different conformations more accurately. Single point calculations for all optimized geometries were performed at the coupled-cluster ${ }^{45}$ level of theory using Dunning's correlation consistent ccpVDZ basis set as implemented in Gaussian 98. In addition, single point energies were also calculated with the B3PW91 method using basis sets of increasing size on B3PW91/6-31G* optimized geometries. Two Pople-type basis sets $\left(6-31 \mathrm{G}^{*}\right.$ and $\left.6-311 \mathrm{G}^{* *}\right)$ and two correlation consistent basis sets (cc-pVDZ and cc-pVTZ) were used as internally available in Gaussian 98.

\section{Results and Discussion}

Geometries: The optimized geometries of sulfur diimides are given in Table 1 and those of selenium diimides in Table 2. In the case of each sulfur diimide studied in this work, the calculated values can be compared with molecular parameters that have been determined by Xray or electron diffraction (see Table 1). The comparison of calculated and experimental geometries indicates that the bond parameters can be predicted reasonably well at all levels of theory. ${ }^{46}$ The RHF/6-31G* calculations underestimate the $\mathrm{S}=\mathrm{N}$ bond lengths by $0.01-0.03 \AA$, whereas at the MP2/6-31G* level they are overestimated by approximately $0.06 \AA$. The $S=\mathrm{N}$ bond lengths yielded by the B3PW91/6-31G* calculations seem to be in best overall agreement 
with the experimental values. The experimental H-N, C-N, and Si-N bond lengths are accurately reproduced at every level of theory. Calculated RMS deviations between the experimental and calculated bond lengths are $0.022,0.041$, and $0.018 \AA$ at the RHF/6-31G*, MP2/6-31G*, and B3PW91/6-31iG* levels of theory, respectively.

With the exception of $\mathrm{S}\left(\mathrm{NH}_{2}\right)_{2}$ and $\mathrm{S}\left(\mathrm{NC}_{6} \mathrm{H}_{3} \mathrm{Me}_{2}-2,6\right)_{2}$ that appear as syn, syn conformers, the experimental molecular structures of all other sulfur diimides shown in Table 1 exhibit syn,anti conformations. ${ }^{47}$ It can also be noted that the two NSN fragments in $\mathrm{S}\left(\mathrm{NSNSiMe}_{3}\right)_{2}{ }^{49}$ and $\mathrm{Se}\left(\mathrm{NSNSiMe}_{3}\right)_{2}{ }^{6}$ also lie in syn,anti conformations. As seen in Table 1, in most cases the $\mathrm{S}=\mathrm{N}$ bond of the $s y n-\mathrm{S}=\mathrm{N}-\mathrm{R}$ fragment is shorter than that corresponding to the anti-S=N-R orientation. This can be rationalized in terms of the bonding description discussed by Sandblom et $a l .{ }^{28}$ While the $\mathrm{S}=\mathrm{N}$ bond lengths generally seem to be independent of the identity of the organic group, those in $\mathrm{S}\left(\mathrm{NSiMe}_{3}\right)_{2}$ are shorter in every conformation. This can be explained by charge delocalization due to the hyperconjugative interaction between the nitrogen $2 p$ lone pair and the $\mathrm{SiMe}_{3}$ fragment. Results from the preliminary ELF ${ }^{50,51}$ calculations for $\mathrm{S}\left(\mathrm{N}^{t} \mathrm{Bu}\right)_{2}$ and $\mathrm{S}\left(\mathrm{NSiMe}_{3}\right)_{2}$ seem to support this conclusion, as they show that the electron population in lone pairs is much smaller in $\mathrm{S}\left(\mathrm{NSiMe}_{3}\right)_{2}$ than in $\mathrm{S}\left(\mathrm{N}^{\mathrm{t}} \mathrm{Bu}\right)_{2}$.

Of the selenium diimides, the $\mathrm{X}$-ray structure is known only for $N, N^{\prime}$-diadamantyl selenium diimide $\mathrm{Se}\left(\mathrm{NC}_{10} \mathrm{H}_{15}\right)_{2},{ }^{33}$ which shows a syn,anti conformation consistent with most sulfur diimides. The experimental $\mathrm{Se}=\mathrm{N}$ bond lengths are 1.679(8) $\AA(s y n-\mathrm{Se}=\mathrm{N}-\mathrm{R})$ and $1.732(7)$ $\AA$ (anti-Se=N-R) displaying a similar trend as syn,anti sulfur diimides. Other estimates for the $\mathrm{Se}=\mathrm{N}$ double bond length can be obtained from the X-ray structures of ${ }^{t} \mathrm{BuNSe}\left(\mu-\mathrm{N}^{t} \mathrm{Bu}\right)_{2} \mathrm{SO}_{2}$ and 
${ }^{t} \mathrm{BuNSe}\left(\mu-\mathrm{N}^{\mathrm{t}} \mathrm{Bu}\right)_{2} \mathrm{SeO} .{ }^{37}$ The exocyclic $\mathrm{Se}=\mathrm{N}$ bonds in these two compounds show lengths of 1.665(2) and 1.687(4) $\AA$, respectively. The optimized $s y n-\mathrm{Se}=\mathrm{N}$ bond lengths for the different syn, anti conformations of $\mathrm{Se}(\mathrm{NR})_{2}$ lie in the range $1.633-1.650,1.708-1.743$, and $1.678-1.702 \AA$ at RHF/6-31G*, MP2/6-31G*, and B3PW91/6-31G* levels of theory, respectively (see Table 2). The corresponding predictions for the anti-Se=N bond lengths are 1.646-1.663, 1.732-1.757, and 1.699-1.722 $\AA$. The calculated $\mathrm{Se}=\mathrm{N}$ bonds in the $s y n-\mathrm{Se}=\mathrm{N}-\mathrm{R}$ fragments are again predicted to be systematically shorter than those in the anti-Se=N-R fragments thus reproducing the experimental trend. Consistent with the bonding arrangement in sulfur diimides, both $\mathrm{Se}=\mathrm{N}$ bonds of $\mathrm{Se}\left(\mathrm{NSiMe}_{3}\right)_{2}$ are shorter than the corresponding bonds in any other selenium diimide.

Although the calculations reproduce the bond lengths relatively accurately, the calculated bond angles show a larger deviation from the experimental values. It can be seen from Table 1 that the NSN bond angles are in good agreement with experimental values (deviations $c a . \pm 1^{\circ}$ ) at each level of theory, but the RHF/6-31G* and MP2/6-31G* optimized SNA $(A=H, C, S i)$ angles deviate from the experimental values. The RHF/6-31G* calculations overestimate the SNA angles, whereas MP2/6-31G* calculations lead to a small underestimation. By contrast, the B3PW91/6-31G* calculations seem to provide a good prediction also for the experimental SNA bond angles. The RMS deviations between the experimental and calculated bond angles are 3.7, 3.4 and $2.3^{\circ}$ at the RHF/6-31G*, MP2/6-31G*, and B3PW91/6-31G* levels of theory, respectively. The optimized NSeN bond angles span a range of 107.2-132.1, 102.8-139.5, and $104.0-136.7^{\circ}$ and the SeNA bond angles $107.1-153.5^{\circ}, 103.1-143.3^{\circ}$, and $104.1-148.8^{\circ}$ at RHF/631G*, MP2/6-31G*, and B3PW91/6-31G* levels, respectively. The experimental NSeN angle in $\mathrm{Se}\left(\mathrm{NC}_{10} \mathrm{H}_{15}\right)_{2}$ is $113.0(6)^{\mathrm{o}}$, and the two SeNC bond angles are $125.0(6)^{\mathrm{o}}$ and $117.6(5)^{\mathrm{o}} .{ }^{33}$ 
Although the bond lengths in the different conformers of the molecules with the same composition do not show significant variation, both the NEN ( $=\mathrm{S}$ or $\mathrm{Se})$ and ENA bond angles are larger in the syn,syn conformations than in the anti,anti conformations for a given group $\mathrm{R}$ (see Figure 2). The NEN angles in the syn,anti conformation expectedly fall between the values for the syn,syn and anti,anti conformations. The syn-ENA angle and the anti-ENA angle in the syn, anti conformation mimic the respective angles in the two symmetric conformations. It can clearly be seen from Figure 2 that the bond angles expectedly get larger, as the R-group becomes bulkier. It can also be noted in Tables 1 and 2 that the ENA angles in selenium diimides are smaller than those in the corresponding sulfur diimides. This indicates that the electronic factors in the bonding arrangement in sulfur and selenium diimides are relatively similar and the molecular geometry depends largely on the steric factors.

The present calculations seem to yield a better agreement between the calculated and experimental bond parameters than the previous theoretical approaches. Semi-empirical CNDO and MNDO calculations ${ }^{11,12,24,25}$ should only be considered as qualitative and the early ab initio calculations ${ }^{26,27}$ have suffered from the use of small, inflexible minimal STO-3G* basis sets that limit the accuracy in the predictions of both molecular geometry and energetics. Sandblom et $a l .{ }^{28}$ have recently reported a DFT study of the conformations and dimerization of $\mathrm{E}(\mathrm{NMe})_{2}(\mathrm{E}=$ $\mathrm{S}, \mathrm{Se}, \mathrm{Te})$. These calculations agree well with the present B3PW91/6-31G* results in the case of $N, N^{\prime}$-dimethyl sulfur diimide with somewhat more pronounced differences in the case of $N, N^{\prime}$ dimethyl selenium diimide. The DFT prediction of Sandblom et al. ${ }^{28}$ yields $\mathrm{Se}=\mathrm{N}$ bond lengths that are $c a .0 .070 \AA$ longer and bond angles that are $2-4^{\circ}$ smaller than the corresponding 
B3PW91/6-31G* values. It seems that generally the B3PW91/6-31G* geometries are in better agreement with experiment than those yielded by the earlier DFT calculations. ${ }^{38}$

Energetics: The total energies and ZPE corrections calculated for sulfur and selenium diimides at RHF/6-31G*, MP2/6-31G*, and B3PW91/6-31G* levels of theory are presented in Supporting Information (Table S1). The relative energies of the different conformations are depicted in Figure 3.

It can be seen from Figure 3 that, with the exception of $\mathrm{E}(\mathrm{NH})_{2}$ for which the syn,syn conformation is most stable, the syn,anti conformation is predicted to be most stable for substituted sulfur and selenium diimides regardless of the level of theory. ${ }^{52}$ In the case of parent $\mathrm{E}(\mathrm{NH})_{2}$, our calculations further confirm the earlier deductions that syn,syn and syn,anti conformations of the parent molecule lie close to each other in energy. These results are expectedly in agreement with the previous experimental ${ }^{11-23}$ and computational 11,12,24-28 findings. The qualitative energy ordering of the different conformations is found to be independent of the level of theory. Results in Figure 3 also show that the anti,anti conformer is more unstable than could be expected on the basis of steric factors alone. Sandblom $\mathrm{et} \mathrm{al.}{ }^{28}$ have recently suggested that the antibonding interaction between the in-plane nitrogen lone pair and the p orbital on sulfur destabilizes the sterically favorable anti,anti conformation.

Quantitative differences in the relative energies can, however, be observed between the calculations carried out at different levels of theory. MP2/6-31G* generally destabilizes the anti,anti conformations and stabilizes the syn,syn conformations by $5-10 \mathrm{~kJ} \mathrm{~mol}^{-1}$ compared to 
RHF/6-31G* calculations. The B3PW91/6-31G* results fall between those from RHF/6-31G* and MP2/6-31G* calculations. The B3PW91/6-31G* energy difference between the syn,syn and syn, anti conformations resembles that extracted from the MP2/6-31G* calculations, while the energy difference between the syn,anti and anti,anti conformations lies closer to that from the RHF/6-31G* calculations than from MP2/6-31G* results.

Since no accurate experimental energetics data are available for chalcogen diimides, the reliability of the results lies solely on the grounds of theory. This was evaluated by high-level CCSD/cc-pVDZ and CCSD(T)/cc-pVDZ calculations. It was not, however, possible to carry out full geometry optimizations at coupled cluster levels of theory. Therefore single point calculations utilizing optimized geometries that were calculated at RHF/6-31G*, MP2/6-31G*, and B3PW91/6-31G* levels of theory (see Tables 1 and 2) were carried out for all sulfur and selenium diimides. The total energies yielded by these calculations are presented in Supporting Information (Table S2). Relative energies are presented at Table 3. The CCSD(T)/ccpVDZ//B3PW91/6-31G* relative energies are shown in Figure 4. The CCSD(T)/cc-pVDZ single point calculations were chosen to utilize B3PW91/6-31G* optimized geometries, since they were in closest agreement with experimental geometries, where available. Furthermore, in most cases, the B3PW91/6-31G* geometries yielded lowest total energies at the CCSD/cc-pVDZ level and could therefore be considered as best geometries at coupled cluster levels of theory. The energetics of the three conformations of the different chalcogen diimides will therefore be discussed below at CCSD(T)/cc-pVDZ//B3PW91/6-31G* level of theory. 
It can be seen from Figures 3 and 4 that the terminal R-group in $\mathrm{E}(\mathrm{NR})_{2}$ seems to have a greater influence on the relative energies of the conformations than the identity of the chalcogen atom. The relative energies for molecules with same substituents but different chalcogen atoms deviate only in the case of tert-butyl diimides, whereas the relative energies for different substituents vary substantially. For example, syn,syn-S(NMe) $)_{2}$ lies $12.2 \mathrm{~kJ} \mathrm{~mol}^{-1}$ and syn,syn$\mathrm{S}\left(\mathrm{N}^{t} \mathrm{Bu}\right)_{2}$ lies $46.8 \mathrm{~kJ} \mathrm{~mol}^{-1}$ above their respective syn, anti conformations, and the syn,syn conformations of $\mathrm{Se}(\mathrm{NMe})_{2}$ and $\mathrm{Se}\left(\mathrm{N}^{t} \mathrm{Bu}\right)_{2}$ lie at 8.3 and $29.9 \mathrm{~kJ} \mathrm{~mol}^{-1}$ above the most stable syn, anti-conformations, respectively (see Figure 4). In the cases of $\mathrm{S}\left(\mathrm{NSiMe}_{3}\right)_{2}$ and $\mathrm{Se}\left(\mathrm{NSiMe}_{3}\right)_{2}$ both the syn,syn and anti,anti conformations lie at almost identical energies of $23.4-25.4 \mathrm{~kJ} \mathrm{~mol}^{-1}$ above the syn, anti conformation.

The CCSD(T)/cc-pVDZ//B3PW91/6-31G* results also indicate that the atomization energies are systematically $c a .90 \mathrm{~kJ} \mathrm{~mol}^{-1}$ smaller for selenium diimides than for corresponding sulfur diimides. ${ }^{53}$ This is consistent with the experimentally observed thermal instability of selenium diimides. ${ }^{29-32}$

The comparison of the $\operatorname{CCSD}(\mathrm{T}) / \mathrm{cc}-\mathrm{pVDZ} / \mathrm{B} 3 \mathrm{PW} 91 / 6-31 \mathrm{G}^{*}$ results with existing computational work indicates that the previous ab initio calculations ${ }^{26,27}$ have predicted that the syn, syn conformations lie lower and the anti,anti conformations lie higher in energy with respect to the syn,anti conformations than what is predicted by the present calculations. The present energy ordering of the three conformations of $\mathrm{S}(\mathrm{NMe})_{2}$ also differs from that reported by Sandblom $e t a l .{ }^{28}$ This divergence can partially be explained by the different methods used in the calculations. ${ }^{38,54} \mathrm{We}$ also note, however, that the geometry optimizations of the syn,syn 
conformations by Sandblom et $a l^{28}$ are carried out by constraining the molecule in $C_{2 \mathrm{v}}$ symmetry. The present RHF/6-31G* and B3PW91/6-31G* level optimizations indicate that the $C_{2 v}$ structure is in fact a first order transition state with respect to the rotation of the methyl groups. Local minimum for the syn, syn conformation was found with $C_{2}$ symmetry, as verified by frequency calculations.

To test the conventional ab initio methods against the chosen B3PW91 functional and to evaluate the reliability of DFT results, B3PW91 single point energies were calculated with more flexible basis sets on B3PW91/6-31G* geometries. The calculated relative energies of different chalcogen diimides are shown in Table 4. These values can be compared to the CCSD(T)/ccpVDZ//B3PW91/6-31G* relative energies that represent the highest level of reliability in the present $a b$ initio calculations (see Table 3). It can clearly be seen from Table 4 that as the size of the basis set is increased, the B3PW91 relative energies show variation, the mutual differences between the basis sets often being above $10 \mathrm{~kJ} \mathrm{~mol}^{-1}$. In the case of the most flexible basis set, cc-pVTZ, the B3PW91 calculations in fact yield relative energies that are furthest away from those obtained by the CCSD(T)/cc-pVDZ//B3PW91/6-31G* level calculations. The smallest Pople-type basis sets seem to reproduce best the high level ab initio relative energies in the case of all sulfur and selenium diimides.

By contrast, it is well-known that the relative energies calculated using $a b$ initio methods converge and become more accurate, when the level of sophistication is increased (See Tables S1 and S2 in Supporting Information). In most cases, the relative energies calculated at MP2/ccpVDZ level of theory can already be considered reasonably reliable. 
These findings seem to contradict the one-dimensionality of the DFT methods i.e. the increase in the size of a basis set should result in a better description of the energy. ${ }^{56}$ It has been stated earlier that "...it is rather plausible that the many honors density functional theory has earned in this field in the past are due to massive error compensation effects arising from the use of a small basis sets". ${ }^{57}$ Large basis sets should therefore not be kept as a definite measure of the quality of DFT results. This has not been explored to its full extent in computational chemistry. It can be very tempting in individual situations to select a basis set that will best reproduce the observed property and hold the method superior, though the agreement between calculated and experimental property might only be fortuitous. Current hybrid density functional methods are fast and valuable means to study structures and chemical properties of molecules. However, as there seems to be no systematic way to improve the accuracy of the DFT calculations, the comparison of the calculated parameters with experimental or sufficiently high-level ab initio data is necessary to evaluate the level of reliability of the results.

\section{Conclusion}

The geometries and energetics of the different conformations of a number of sulfur and selenium diimides $\mathrm{E}(\mathrm{NR})_{2}\left(\mathrm{E}=\mathrm{S}, \mathrm{Se} ; \mathrm{R}=\mathrm{H}, \mathrm{Me},{ }^{\mathrm{t}} \mathrm{Bu}, \mathrm{C}_{6} \mathrm{H}_{3} \mathrm{Me}_{2}-2,6, \mathrm{SiMe}_{3}\right)$ have been studied by using $a b$ initio and DFT molecular orbital techniques. With the exception of parent $\mathrm{E}(\mathrm{NH})_{2}$, for which the syn,syn conformation is most stable, the syn,anti conformation is predicted to be most stable for substituted sulfur and selenium diimides regardless of the level of theory. In the case of 
parent $\mathrm{E}(\mathrm{NH})_{2}$, the present calculations further confirm that syn,syn and syn,anti conformations lie close to each other.

The geometry optimizations were carried out at $\mathrm{RHF} / 6-31 \mathrm{G}^{*}$, MP2/6-31G*, and B3PW91/6-31G* levels of theory. B3PW91/6-31G* proved to be the most suitable method for reproducing the experimental geometries of chalcogen diimides. It has a speed advantage compared to $a b$ initio methods and provides results of at least the same accuracy as computationally much more demanding MP2/6-31G*.

The total and relative energies of the different conformations of $\mathrm{S}(\mathrm{NR})_{2}$ and $\mathrm{Se}(\mathrm{NR})_{2}$ molecules have been calculated at RHF/6-31G*, MP2/6-31G*, and B3PW91/6-31G* levels of theory and compared with those yielded by higher-level $\operatorname{CCSD}(\mathrm{T})$ and B3PW91 calculations. The qualitative energy ordering of the different conformations is found to be independent of the level of theory. By contrast, the quantitative energy differences are found to be dependent on the method. Whereas ab initio methods yield increasingly accurate relative energies with increasing level of theory, B3PW91 results show divergence, as the size of the basis set is increased. The B3PW91 involving small Pople-type basis sets seem to reproduce best the energetics of chalcogen diimides from high-level $a b$ initio calculations. Since the B3PW91/6-31G* calculations predict well the optimum geometries, reliable relative energies of the chalcogen diimide conformers can conveniently be computed at $\operatorname{CCSD(T)/cc-pVDZ//B3PW91/6-31G*~}$ level of theory. 
It is well established experimentally that, whereas sulfur diimides $\mathrm{S}(\mathrm{NR})_{2}$ exist as monomeric species in solution, the corresponding tellurium diimides $\mathrm{Te}(\mathrm{NR})_{2}$ undergo a facile $[2+2]$ cycloaddition reaction to form dimeric $\operatorname{RNTe}(\mu-\mathrm{NR})_{2} \mathrm{TeNR}^{34-36}$ It is not quite clear whether selenium diimides are preferentially monomeric or dimeric. The NMR spectroscopic evidence of selenium diimides in solution ${ }^{31}$ as well as the X-ray structure of $N, N^{\prime}$-diadamantyl selenium diimide ${ }^{33}$ indicate a preference for monomeric structures, but [2+2] cycloaddition reactions have been inferred for the dimerization of ${ }^{\mathrm{t}} \mathrm{BuNSeO}$ to $\mathrm{OSe}\left(\mu-{ }^{\mathrm{t}} \mathrm{BuN}\right)_{2} \mathrm{SeO}{ }^{33}$ and for the reaction of ${ }^{t} \mathrm{BuNSeO}$ and $\mathrm{Se}\left(\mathrm{N}^{\mathrm{t}} \mathrm{Bu}\right)_{2}$ that affords ${ }^{\mathrm{t}} \mathrm{BuNSe}\left(\mathrm{N}^{\mathrm{t}} \mathrm{Bu}\right)_{2} \mathrm{SeO} .{ }^{37}$ The DFT calculations of Sandblom et $a l .{ }^{28}$ have indicated that the cycloaddition reactions of sulfur diimides are strongly endothermic, those of selenium diimides are approximately thermally neutral, and those involving tellurium diimides are strongly exothermic. Since the present calculations demonstrate that the relative energies of various chalcogen diimide monomers are dependent on the method and level of theory, it is conceivable that the energetics of cycloaddition is also affected by the computational approach. Calculations to explore the cycloaddition process at different levels of theory are currently in progress.

Acknowledgements: Financial support from the Ministry of Education in Finland and Academy of Finland is gratefully acknowledged. We also thank the Finnish National Center of Scientific Computing for allocation of CPU time.

Supporting Information Available: Total energies of sulfur and selenium diimides calculated at different levels of theory (Tables S1 and S2). This material is available free of charge via the Internet at http://pubs.acs.org. 


\section{References:}

(1) Vrieze, K.; van Koten, G. Recl. Trav. Chim. Pays-Bas 1980, 99, 145.

(2) Chivers, T.; Hilts, R.W. Coord. Chem. Rev. 1994, 137, 201.

(3) Hill, A. Organomet. Chem. Rev. 1994, 36, 159.

(4) Bussas, R.; Kresze, G.; Münsterer, H.; Schwöbel, A. Sulphur Rep. 1983, 2, 215.

(5) For recent reviews, see Ref. 6.

(6) Konu, J.; Maaninen, A.; Paananen, K.; Ingman, P.; Laitinen, R.S.; Chivers, T.; Valkonen, J. Inorg. Chem. 2002, 41, 1430, and references therein.

(7) Grunwell, J.R.; Hoyng, C.F.; Rieck, J.A. Tetrahedron Lett. 1973, 26, 2421.

(8) Kuyper, J.; Vrieze, K. J. Organomet. Chem. 1974, 74, 289.

(9) Kuyper, J.; Vrieze, K. J. Organomet. Chem. 1975, 86, 127.

(10) Sicinska, W.; Stefaniak, L.; Witanowski, M.; Webb, G.A. J. Mol. Struct. 1987, 158, 57.

(11) Bagryanskaya, I.Yu.; Gatilov, Y.; Shakirov, M.M.; Zibarev, A.V. Mendeleev. Commun. 1994, 136.

(12) Bagryanskaya, I.Yu.; Gatilov, Y.; Shakirov, M.M.; Zibarev, A.V. Mendeleev. Commun. 1994, 167.

(13) Leandri, G.; Busetti, V.; Valle, G.; Mammi, M. Chem. Commun. 1970, 413.

(14) Leitch, J.; Nyburg, S.C.; Armitage, D.A.; Clark, M.J. J. Cryst. Mol. Struct. 1973, 3, 337.

(15) Olsen, F.P.; Barrick, J.C. Inorg. Chem. 1973, 12, 1353.

(16) Kuyper, J.; Isselmann, P.H.; Mijlhoff, F.C.; Spelbos, A.; Renes, G. J. Mol. Struct. 1975, $29,247$.

(17) Busetti, V. Acta Crystallogr. 1982, B38, 665.

(18) Suenram, R.D.; Lovas, F.J.; Stevens, W.J. J. Mol. Spect. 1985, 112, 482. 
(19) Anderson, D.G.; Robertson, H.E.; Rankin, D.W.H.; Woollins, J.D. J. Chem. Soc., Dalton Trans. 1989, 859.

(20) Herberhold, M.; Gerstmann, S.; Wrackmeyer, B.; Borrmann, H. J. Chem. Soc., Dalton Trans. 1994, 5, 633.

(21) Herberhold, M.; Gerstmann, S.; Milius, W.; Wrackmeyer, B.; Borrmann, H. Phosphorus, Sulfur Silicon Relat. Elem. 1996, 112, 261.

(22) Lork, E.; Mews, R.; Shakirov, M.M.; Watson, P.G.; Zibarev, A.V. Eur. J. Inorg. Chem. 2001, 2123.

(23) Zibarev, A.V.; Gatilov, Y.V.; Bagryanskaya, I.Yu.; Konchenko, S.N. Polyhedron 1992, $11,2787$.

(24) Grunwell, J. R.; Danison W.C. Tetrahedron 1971, 27, 5315.

(25) Issa, Y.; Hossain, F. B. S.; Davood, N. S. J. Mol. Struct. 1996, 364, 79.

(26) Raghavachari, K.; Haddon, R.C. J. Phys. Chem. 1983, 87, 1308.

(27) Millefiori, S.; Millefiori, A.; Granozzi, G. Inorg. Chim. Acta 1984, 90, 105.

(28) Sandblom, N.; Ziegler, T.; Chivers, T. Inorg. Chem. 1998, 37, 354.

(29) Herberhold, M.; Jellen, W. Z. Naturforsch., Teil B 1986, 41b, 144.

(30) Sharpless, K. B.; Hori, T.; Truesdale, L. K.; Dietrich, C. O. J. Am. Chem. Soc. 1976, 98, 269.

(31) Wrackmeyer, B.; Distler, B.; Gerstmann, S.; Herberhold, M. Z. Naturforsch. 1993, 48b, 1307.

(32) Fockenberg, F.; Haas, A. Z. Naturforsch. Sect. B 1986, 41b, 413.

(33) Maaninen, T.; Laitinen, R.; Chivers, T. Chem. Commun. 2002, 1812.

(34) Chivers, T.; Gao, X.; Parvez, M. J. Chem. Soc., Chem. Commun. 1994, 2149. 
(35) Chivers, T.; Gao, X.; Parvez, M. J. Am. Chem. Soc. 1995, 117, 2359.

(36) Chivers, T.; Gao, X.; Parvez, M. Inorg. Chem. 1996, 35, 9.

(37) Maaninen, T.; Chivers, T.; Laitinen, R.S.; Schatte, G.; Nissinen, M. Inorg. Chem. 2000, $39,5341$.

(38) These calculations were based on DFT within the local density approximation. In addition, Becke's nonlocal exchange correction and Perdew's inhomogeneous gradient corrections for correlation were used. A double-zeta STO basis sets were used for the ns and np shells of the main group elements. The basis sets were augmented by a single $3 \mathrm{~d}$ STO polarization function (2p STO for hydrogen). For full details of the calculation, see Ref. 28 and references therein.

(39) Frisch, M. J.; Trucks; G. W.; Schlegel, H. B.; Scuseria, G. E.; Robb, M. A.; Cheeseman, J. R.; Zakrzewski, V. G.; Montgomery, J. A Jr.; Stratmann, R. E.; Burant, J. C.; Dapprich, S.; Millam, J. M.; Daniels, A. D.; Kudin, K. N.; Strain, M. C.; Farkas, O.; Tomasi, J.; Barone, V.; Cossi, M.; Cammi, R.; Mennucci, B.; Pomelli, C.; Adamo, C.; Clifford, S.; Ochterski, J.; Petersson, G. A.; Ayala, P. Y.; Cui, Q.; Morokuma, K.; Salvador, P.; Dannenberg, J. J.; Malick, D. K.; Rabuck, A. D.; Raghavachari, K.; Foresman, J. B.; Cioslowski, J.; Ortiz, J. V.; Baboul, A. G.; Stefanov, B. B.; Liu, G.; Liashenko, A.; Piskorz, P.; Komaromi, I.; Gomperts, R.; Martin, R. L.; Fox, D. J.; Keith, D. J.; AlLaham, M. A.; Peng, C. Y.; Nanayakkara, A.; Challacombe, M.; Gill, P. M. W.; Johnson, B.; Chen, B.; Wong, M. W.; Andres, J. L.; Gonzalez, C.; Head-Gordon, M.; Replogle, E. S.; Pople, J. A., Gaussian 98 (Revision A.11), Gaussian, Inc., Pittsburgh PA, 2001.

(40) Roothaan, C. C. J. Rev. Mod. Phys. 1951, 23, 69.

(41) Møller, C.; Plesset, M. S. Phys. Rev. 1934, 46, 618. 
(42) Becke, A. D. J. Chem. Phys. 1993, 98, 5648.

(43) Perdew, J. P.; Wang, Y. Phys. Rev. B 1992, 45, 13244.

(44) Redfern, P. C.; Blaudeau, J. P.; Curtiss, L. A. J. Phys. Chem. A 1997, 101, 8701.

(45) Bartlett, R. J. J. Phys. Chem. 1989, 93, 1697, and references therein.

(46) It should be noted, however, that the two phenyl rings of anti,anti 2,6dimethylphenylsulfur diimide are predicted to be coplanar with the NSN fragment at B3PW91/6-31G* level of theory and almost perpendicular to the NSN plane at MP2/6$31 \mathrm{G}^{*}$ level of theory. While there is no experimental information for this conformation, the known molecular structures of several sulfur diimides containing an aromatic substituent bound to the nitrogen atoms of the NSN fragment demonstrate that the plane of the ring can indeed assume several different orientations from coplanarity to being perpendicular to the plane of the NSN fragment, ${ }^{11-15,17}$ therefore implying low energy barriers to internal rotation.

(47) There have been conflicting reports about the conformation of $\mathrm{S}\left(\mathrm{NSiMe}_{3}\right)_{2}$. The assignment of IR and Raman spectra could be made in terms of a distorted anti,anti conformation. ${ }^{48}$ The electron diffraction data of a gaseous sample were interpreted in terms of a syn,syn conformation, ${ }^{19}$ while the solid state structure could unambiguously be determined to show a syn, anti conformer by X-ray crystallography. ${ }^{20}$

(48) Herbrechtsmeier, A.; Schnebel, F.-M.; Glemser, O. J. Mol. Struct. 1978, 50, 43.

(49) Bagryanskaya, I.Yu.; Gatilov, Y.V.; Shakirov, M.M.; Zibarev, A.V., J. Struct. Chem. 1996, 37, 318.

(50) Noury, S.; Krokidis, X.; Fuster F.; Silvi, B. TopMoD program package, Universite Pierre et Marie Curie, 1997. 
(51) Malcolm, N. O. J.; Gillespie, R. J.; Popelier, P. L. A. J. Chem. Soc., Dalton Trans. 2002, 17,3333 .

(52) The second exception is $\mathrm{S}\left(\mathrm{NC}_{6} \mathrm{H}_{3} \mathrm{Me}_{2}-2,6\right)_{2}$ for which the syn, syn conformation is also most stable in agreement with the experimental observation. ${ }^{11}$ The syn,anti conformation lies $2.8 \mathrm{~kJ} \mathrm{~mol}^{-1}$ and the anti,anti conformation $18.9 \mathrm{~kJ} \mathrm{~mol}^{-1}$ above the syn,syn conformation at B3PW91/6-31G* level of theory (see Table S1 in Supporting Information for total energies and ZPE corrections).

(53) CCSD(T)/cc-pVDZ total energies (a.u.) for free H, C, N, Si, S and Se atoms are -0.49928, $-37.76038,-54.47850,-288.91509,-397.60055$ and -2399.89854 , respectively.

(54) It has recently been concluded that the hybrid functionals generally perform better than LDA and GGA approaches (see Ref. 55, p. 124, and references therein).

(55) Koch, W.; Holthausen, M.C. A Chemist's Guide to Density Functional Theory, VCH: Weinheim 2001.

(56) Jensen, F. Introduction to Computational Chemistry, John Wiley \& Sons: Chichester, 1999.

(57) See Ref. 55, p. 246. 
Table 1. The RHF/6-31G*, MP2/6-31G*, and B3PW91/6-31G* Optimized Geometries of Sulfur Diimides $\mathrm{S}(\mathrm{NR})_{2}\left(\mathrm{R}=\mathrm{H}, \mathrm{Me}\right.$, ${ }^{\mathrm{t}} \mathrm{Bu}$, $\mathrm{C}_{6} \mathrm{H}_{3} \mathrm{Me}_{2}-2,6, \mathrm{SiMe}_{3} ; \mathrm{A}=\mathrm{H}, \mathrm{C}, \mathrm{Si}$ )

\begin{tabular}{|c|c|c|c|c|c|c|c|c|}
\hline Molecule & Method & $r\left(\mathrm{SN}_{1}\right)$ & $r\left(\mathrm{SN}_{2}\right)$ & $r\left(\mathrm{~N}_{1} \mathrm{~A}\right)$ & $r\left(\mathrm{~N}_{2} \mathrm{~A}\right)$ & $\angle \mathrm{NSN}$ & $\angle \mathrm{SN}_{1} \mathrm{~A}$ & $\angle \mathrm{SN}_{2} \mathrm{~A}$ \\
\hline \multicolumn{9}{|l|}{$\mathrm{S}(\mathrm{NH})_{2}$} \\
\hline \multirow[t]{4}{*}{$(s, s)$} & RHF & 1.507 & & 1.006 & & 122.2 & 117.8 & \\
\hline & MP2 & 1.569 & & 1.030 & & 124.2 & 115.2 & \\
\hline & B3PW91 & 1.549 & & 1.025 & & 124.1 & 116.2 & \\
\hline & Exptl. $^{\mathrm{a}}$ & $1.533(7)$ & & $1.025(15)$ & & $124.0(9)$ & $115.4(8)$ & \\
\hline \multirow[t]{3}{*}{$(a, a)$} & RHF & 1.507 & & 1.004 & & 112.7 & 108.8 & \\
\hline & MP2 & 1.573 & & 1.028 & & 108.8 & 105.6 & \\
\hline & B3PW91 & 1.552 & & 1.024 & & 110.0 & 106.1 & \\
\hline \multirow[t]{3}{*}{$(s, a)$} & RHF & 1.501 & 1.513 & 1.007 & 1.004 & 116.2 & 115.2 & 110.1 \\
\hline & MP2 & 1.560 & 1.578 & 1.032 & 1.029 & 114.7 & 111.9 & 107.3 \\
\hline & B3PW91 & 1.541 & 1.558 & 1.027 & 1.025 & 115.5 & 113.1 & 107.8 \\
\hline \multicolumn{9}{|l|}{$\mathrm{S}(\mathrm{NMe})_{2}$} \\
\hline \multirow[t]{3}{*}{$(s, s)$} & RHF & 1.502 & & 1.447 & & 125.2 & 130.7 & \\
\hline & MP2 & 1.576 & & 1.464 & & 127.5 & 126.8 & \\
\hline & B3PW91 & 1.549 & & 1.448 & & 127.2 & 129.2 & \\
\hline \multirow[t]{3}{*}{$(a, a)$} & RHF & 1.505 & & 1.453 & & 113.2 & 116.8 & \\
\hline & MP2 & 1.581 & & 1.471 & & 109.6 & 112.5 & \\
\hline & B3PW91 & 1.555 & & 1.456 & & 110.5 & 114.2 & \\
\hline \multirow[t]{4}{*}{$(s, a)$} & RHF & 1.501 & 1.513 & 1.449 & 1.453 & 115.9 & 122.0 & 117.6 \\
\hline & MP2 & 1.573 & 1.592 & 1.463 & 1.471 & 113.5 & 116.9 & 113.5 \\
\hline & B3PW91 & 1.547 & 1.564 & 1.449 & 1.456 & 114.7 & 119.6 & 115.2 \\
\hline & Exptl. ${ }^{b}$ & $1.532(10)$ & $1.532(10)$ & $1.464(18)$ & $1.464(18)$ & $113.6(16)$ & $124.3(12)$ & $116.5(12)$ \\
\hline
\end{tabular}


Table 1. Continued

\begin{tabular}{|c|c|c|c|c|c|c|c|c|}
\hline Molecule & Method & $r\left(\mathrm{SN}_{1}\right)$ & $r\left(\mathrm{SN}_{2}\right)$ & $r\left(\mathrm{~N}_{1} \mathrm{~A}\right)$ & $r\left(\mathrm{~N}_{2} \mathrm{~A}\right)$ & $\angle \mathrm{NSN}$ & $\angle \mathrm{SN}_{1} \mathrm{~A}$ & $\angle \mathrm{SN}_{2} \mathrm{~A}$ \\
\hline \multicolumn{9}{|l|}{$\mathbf{S}\left(\mathbf{N}^{t} \mathbf{B u}\right)_{2}$} \\
\hline \multirow[t]{3}{*}{$(s, s)$} & RHF & 1.492 & & 1.458 & & 131.5 & 147.3 & \\
\hline & MP2 & 1.584 & & 1.464 & & 137.2 & 141.0 & \\
\hline & B3PW91 & 1.544 & & 1.459 & & 134.9 & 143.7 & \\
\hline \multirow[t]{3}{*}{$(a, a)$} & RHF & 1.504 & & 1.470 & & 112.0 & 121.9 & \\
\hline & MP2 & 1.586 & & 1.482 & & 107.7 & 117.0 & \\
\hline & B3PW91 & 1.555 & & 1.473 & & 109.1 & 118.7 & \\
\hline \multirow[t]{4}{*}{$(s, a)$} & RHF & 1.498 & 1.510 & 1.469 & 1.472 & 118.3 & 130.6 & 122.3 \\
\hline & MP2 & 1.573 & 1.598 & 1.476 & 1.483 & 116.7 & 125.5 & 117.7 \\
\hline & B3PW91 & 1.542 & 1.565 & 1.472 & 1.476 & 117.6 & 128.1 & 119.1 \\
\hline & Exptl. $^{c}$ & $1.530(12)$ & $1.545(11)$ & $1.480(15)$ & $1.492(12)$ & $117.41(3)$ & $127.95(5)$ & $118.22(4)$ \\
\hline \multicolumn{9}{|c|}{ S(NSiMe3)2 } \\
\hline \multirow[t]{3}{*}{$(s, s)$} & RHF & 1.482 & & 1.739 & & 123.3 & 155.8 & \\
\hline & MP2 & 1.549 & & 1.768 & & 126.4 & 147.4 & \\
\hline & B3PW91 & 1.525 & & 1.752 & & 125.1 & 152.0 & \\
\hline \multirow[t]{3}{*}{$(a, a)$} & RHF & 1.489 & & 1.746 & & 115.6 & 132.7 & \\
\hline & MP2 & 1.556 & & 1.776 & & 112.6 & 123.4 & \\
\hline & B3PW91 & 1.534 & & 1.761 & & 113.3 & 127.2 & \\
\hline \multirow[t]{4}{*}{$(s, a)$} & RHF & 1.488 & 1.499 & 1.765 & 1.750 & 118.2 & 134.9 & 131.6 \\
\hline & MP2 & 1.569 & 1.592 & 1.795 & 1.779 & 116.9 & 126.5 & 124.1 \\
\hline & B3PW91 & 1.529 & 1.545 & 1.778 & 1.765 & 117.9 & 132.2 & 126.6 \\
\hline & Exptl. $^{d}$ & $1.5155(6)$ & $1.5230(5)$ & $1.7585(6)$ & $1.7593(5)$ & $117.77(3)$ & $129.78(4)$ & $123.29(3)$ \\
\hline
\end{tabular}


Table 1. Continued

\begin{tabular}{|c|c|c|c|c|c|c|c|c|}
\hline Molecule & Method & $r\left(\mathrm{SN}_{1}\right)$ & $r\left(\mathrm{SN}_{2}\right)$ & $r\left(\mathrm{~N}_{1} \mathrm{~A}\right)$ & $r\left(\mathrm{~N}_{2} \mathrm{~A}\right)$ & $\angle \mathrm{NSN}$ & $\angle \mathrm{SN}_{1} \mathrm{~A}$ & $\angle \mathrm{SN}_{2} \mathrm{~A}$ \\
\hline \multicolumn{9}{|c|}{$\mathrm{S}\left(\mathrm{NC}_{6} \mathrm{H}_{3} \mathrm{Me}_{2}\right)_{2}$} \\
\hline \multirow[t]{4}{*}{$(s, s)$} & RHF & 1.499 & & 1.409 & & 127.4 & 138.0 & \\
\hline & MP2 & 1.602 & & 1.408 & & 124.1 & 124.4 & \\
\hline & B3PW91 & 1.554 & & 1.397 & & 128.9 & 136.3 & \\
\hline & Exptl. $^{e}$ & $1.526(2)$ & & $1.423(3)$ & & $127.2(2)$ & $131.8(2)$ & \\
\hline \multirow[t]{3}{*}{$(a, a)$} & RHF & 1.507 & & 1.427 & & 111.8 & 117.4 & \\
\hline & MP2 & 1.591 & & 1.436 & & 108.7 & 110.8 & \\
\hline & B3PW91 & 1.573 & & 1.379 & & 104.3 & 128.6 & \\
\hline \multirow[t]{3}{*}{$(s, a)$} & RHF & 1.499 & 1.512 & 1.416 & 1.422 & 117.1 & 129.6 & 119.8 \\
\hline & MP2 & 1.580 & 1.598 & 1.416 & 1.433 & 115.2 & 123.7 & 112.9 \\
\hline & B3PW91 & 1.550 & 1.568 & 1.399 & 1.401 & 115.4 & 130.3 & 123.6 \\
\hline
\end{tabular}

${ }^{a}$ Ref. 18. ${ }^{b}$ Ref. 16. ${ }^{c}$ Ref. 21. ${ }^{d}$ Ref. 20. ${ }^{e}$ Ref. 11. 
Table 2. The RHF/6-31G*, MP2/6-31G*, and B3PW91/6-31G* Optimized Geometries of Selenium Diimides Se(NR)2 $(\mathrm{R}=\mathrm{H}, \mathrm{Me}$, ${ }^{\mathrm{t}} \mathrm{Bu}, \mathrm{SiMe}_{3} ; \mathrm{A}=\mathrm{H}, \mathrm{C}, \mathrm{Si}$ ).

\begin{tabular}{|c|c|c|c|c|c|c|c|c|}
\hline Molecule & Method & $r\left(\mathrm{SeN}_{1}\right)$ & $r\left(\mathrm{SeN}_{2}\right)$ & $r\left(\mathrm{~N}_{1} \mathrm{~A}\right)$ & $r\left(\mathrm{~N}_{2} \mathrm{~A}\right)$ & $\angle \mathrm{NSeN}$ & $\angle \mathrm{SeN}_{1} \mathrm{~A}$ & $\angle \mathrm{SeN}_{2} \mathrm{~A}$ \\
\hline \multicolumn{9}{|l|}{$\mathrm{Se}(\mathrm{NH})_{2}$} \\
\hline \multirow[t]{3}{*}{$(s, s)$} & RHF & 1.655 & & 1.007 & & 119.2 & 114.0 & \\
\hline & MP2 & 1.729 & & 1.034 & & 121.8 & 111.1 & \\
\hline & B3PW91 & 1.702 & & 1.027 & & 120.9 & 111.5 & \\
\hline \multirow[t]{3}{*}{$(a, a)$} & RHF & 1.655 & & 1.006 & & 108.2 & 107.1 & \\
\hline & MP2 & 1.733 & & 1.034 & & 104.3 & 103.1 & \\
\hline & B3PW91 & 1.704 & & 1.027 & & 105.3 & 104.1 & \\
\hline \multirow[t]{3}{*}{$(s, a)$} & RHF & 1.649 & 1.660 & 1.008 & 1.006 & 112.1 & 111.3 & 108.6 \\
\hline & MP2 & 1.721 & 1.737 & 1.037 & 1.034 & 110.9 & 107.7 & 104.9 \\
\hline & B3PW91 & 1.694 & 1.710 & 1.029 & 1.027 & 111.0 & 108.5 & 105.8 \\
\hline \multicolumn{9}{|l|}{$\mathrm{Se}(\mathrm{NMe})_{2}$} \\
\hline \multirow[t]{3}{*}{$(s, s)$} & RHF & 1.651 & & 1.446 & & 123.4 & 128.8 & \\
\hline & MP2 & 1.741 & & 1.465 & & 126.4 & 124.8 & \\
\hline & B3PW91 & 1.705 & & 1.447 & & 125.6 & 126.6 & \\
\hline \multirow[t]{3}{*}{$(a, a)$} & RHF & 1.653 & & 1.451 & & 108.8 & 116.5 & \\
\hline & MP2 & 1.744 & & 1.475 & & 105.6 & 111.6 & \\
\hline & B3PW91 & 1.708 & & 1.455 & & 106.0 & 113.7 & \\
\hline \multirow[t]{3}{*}{$(s, a)$} & RHF & 1.650 & 1.660 & 1.449 & 1.451 & 111.8 & 119.8 & 117.6 \\
\hline & MP2 & 1.738 & 1.757 & 1.466 & 1.474 & 108.9 & 113.9 & 112.9 \\
\hline & B3PW91 & 1.702 & 1.717 & 1.449 & 1.455 & 109.9 & 116.8 & 115.0 \\
\hline
\end{tabular}


Table 2. Continued

\begin{tabular}{|c|c|c|c|c|c|c|c|c|}
\hline Molecule & Method & $r\left(\mathrm{SeN}_{1}\right)$ & $r\left(\mathrm{SeN}_{2}\right)$ & $r\left(\mathrm{~N}_{1} \mathrm{~A}\right)$ & $r\left(\mathrm{~N}_{2} \mathrm{~A}\right)$ & $\angle \mathrm{NSeN}$ & $\angle \mathrm{SeN}_{1} \mathrm{~A}$ & $\angle \mathrm{SeN}_{2} \mathrm{~A}$ \\
\hline \multicolumn{9}{|l|}{$\operatorname{Se}\left(N^{t} B u\right)_{2}$} \\
\hline \multirow[t]{3}{*}{$(s, s)$} & RHF & 1.646 & & 1.454 & & 132.1 & 143.4 & \\
\hline & MP2 & 1.760 & & 1.459 & & 139.5 & 136.7 & \\
\hline & B3PW91 & 1.708 & & 1.453 & & 136.7 & 139.1 & \\
\hline \multirow[t]{3}{*}{$(a, a)$} & RHF & 1.653 & & 1.467 & & 107.2 & 120.5 & \\
\hline & MP2 & 1.753 & & 1.485 & & 102.8 & 114.4 & \\
\hline & B3PW91 & 1.710 & & 1.471 & & 104.0 & 116.7 & \\
\hline \multirow[t]{3}{*}{$(s, a)$} & RHF & 1.645 & 1.663 & 1.466 & 1.476 & 115.4 & 128.3 & 118.6 \\
\hline & MP2 & 1.743 & 1.757 & 1.474 & 1.491 & 114.8 & 122.8 & 114.3 \\
\hline & B3PW91 & 1.696 & 1.722 & 1.467 & 1.482 & 114.8 & 125.4 & 115.0 \\
\hline \multicolumn{9}{|c|}{$\mathrm{Se}(\mathrm{NSiMe})_{2}$} \\
\hline \multirow[t]{3}{*}{$(s, s)$} & RHF & 1.638 & & 1.730 & & 121.5 & 153.5 & \\
\hline & MP2 & 1.711 & & 1.766 & & 127.3 & 143.3 & \\
\hline & B3PW91 & 1.676 & & 1.744 & & 124.3 & 148.8 & \\
\hline \multirow[t]{3}{*}{$(a, a)$} & RHF & 1.636 & & 1.741 & & 110.7 & 128.3 & \\
\hline & MP2 & 1.715 & & 1.715 & & 108.4 & 118.3 & \\
\hline & B3PW91 & 1.685 & & 1.757 & & 108.3 & 122.5 & \\
\hline \multirow[t]{3}{*}{$(s, a)$} & RHF & 1.633 & 1.646 & 1.757 & 1.745 & 114.8 & 131.6 & 126.4 \\
\hline & MP2 & 1.708 & 1.732 & 1.791 & 1.783 & 114.5 & 122.9 & 117.0 \\
\hline & B3PW91 & 1.678 & 1.699 & 1.771 & 1.763 & 114.5 & 128.0 & 119.9 \\
\hline \multicolumn{9}{|c|}{$\mathrm{Se}\left(\mathrm{NC}_{10} \mathrm{H}_{15}\right)_{2}$} \\
\hline
\end{tabular}

${ }^{a}$ Ref. 33. 
Table 3. Relative Energies $\left(\mathrm{kJ} \mathrm{mol}^{-1}\right)$ of Sulfur and Selenium Diimide Conformations at CCSD/cc-pVDZ and CCSD(T)/cc-pVDZ Levels of Theory Utilizing Geometries Optimized at Different Levels of Theory. ${ }^{a}$

\begin{tabular}{|c|c|c|c|c|c|c|c|c|c|}
\hline Molecule & $\begin{array}{c}\text { CCSD/ } \\
\text { cc-pVDZ// } \\
\text { RHF/ } \\
\text { 6-31G* }\end{array}$ & $\begin{array}{c}\text { CCSD/cc- } \\
\text { pVDZ// } \\
\text { MP2/ } \\
\text { 6-31G* }\end{array}$ & $\begin{array}{c}\text { CCSD/cc- } \\
\text { pVDZ// } \\
\text { B3PW91/ } \\
\text { 6-31G* }\end{array}$ & $\begin{array}{c}\mathrm{CCSD}(\mathrm{T}) / \mathrm{cc} \\
\text {-pVDZ// } \\
\text { B3PW91/ } \\
\text { 6-31G* }\end{array}$ & Molecule & $\begin{array}{c}\text { CCSD/cc- } \\
\text { pVDZ// } \\
\text { RHF/ } \\
6-31 G^{*}\end{array}$ & $\begin{array}{c}\text { CCSD/cc- } \\
\text { pVDZ// } \\
\text { MP2/ } \\
6-31 G^{*}\end{array}$ & $\begin{array}{c}\text { CCSD/cc- } \\
\text { pVDZ// } \\
\text { B3PW91/ } \\
6-31 G^{*}\end{array}$ & $\begin{array}{c}\mathrm{CCSD}(\mathrm{T}) / \mathrm{cc} \\
\text {-pVDZ// } \\
\text { B3PW91/ } \\
\text { 6-31G* }\end{array}$ \\
\hline $\begin{array}{l}\text { S(NH)2 } \\
(s, s)\end{array}$ & 0.0 & 0.0 & 0.0 & 0.0 & $\begin{array}{l}\mathbf{S e}(\mathbf{N H})_{2} \\
(s, s)\end{array}$ & 0.0 & 0.0 & 0.0 & 0.0 \\
\hline$(a, a)$ & 26.9 & 23.3 & 23.5 & 23.3 & $(a, a)$ & 25.8 & 23.5 & 24.0 & 23.0 \\
\hline$(s, a)$ & 4.9 & 3.9 & 4.2 & 4.7 & $(s, a)$ & 6.6 & 5.9 & 6.5 & 6.9 \\
\hline $\begin{array}{l}\mathbf{S}(\mathbf{N M e})_{2} \\
(s, s)\end{array}$ & 12.0 & 12.4 & 12.9 & 12.2 & $\begin{array}{l}\mathrm{Se}(\mathrm{NMe})_{2} \\
(s, s)\end{array}$ & 7.3 & 8.8 & 9.6 & 8.3 \\
\hline$(a, a)$ & 35.3 & 33.7 & 33.5 & 34.2 & $(a, a)$ & 33.1 & 31.4 & 31.7 & 31.8 \\
\hline$(s, a)$ & 0.0 & 0.0 & 0.0 & 0.0 & $(s, a)$ & 0.0 & 0.0 & 0.0 & 0.0 \\
\hline $\begin{array}{l}\mathbf{S}\left(\mathbf{N}^{t} \mathbf{B u}\right)_{2} \\
(s, s)\end{array}$ & 51.9 & 49.2 & 48.7 & 46.8 & $\begin{array}{l}\mathbf{S e}\left(\mathbf{N}^{t} \mathbf{B u}\right)_{2} \\
(s, s)\end{array}$ & 35.4 & 38.1 & 33.7 & 32.2 \\
\hline$(a, a)$ & 31.7 & 30.5 & 30.5 & 33.4 & $(a, a)$ & 30.8 & 30.2 & 30.1 & 29.9 \\
\hline$(s, a)$ & 0.0 & 0.0 & 0.0 & 0.0 & $(s, a)$ & 0.0 & 0.0 & 0.0 & 0.0 \\
\hline $\begin{array}{l}\mathbf{S}(\mathbf{N S i M e})_{2} \\
(s, s)\end{array}$ & 27.2 & 26.1 & 26.0 & 25.4 & $\begin{array}{l}\mathrm{Se}\left(\mathrm{NSiMe}_{3}\right)_{2} \\
(s, s)\end{array}$ & 25.5 & 22.2 & 23.7 & 23.4 \\
\hline$(a, a)$ & 26.0 & 24.7 & 23.7 & 25.2 & $(a, a)$ & 23.8 & 23.0 & 24.1 & 25.2 \\
\hline$(s, a)$ & 0.0 & 0.0 & 0.0 & 0.0 & $(s, a)$ & 0.0 & 0.0 & 0.0 & 0.0 \\
\hline
\end{tabular}

${ }^{a}$ Unscaled zero-point energy corrections for the relative energies has been made at B3PW91/6-31G* level of theory. 
Table 4. The Dependence of the B3PW91 Relative Energies on the Basis Sets. The Geometry Optimization and the ZPE Correction Have Been Carried Out at B3PW91/6-31G* Level of Theory.

\begin{tabular}{|c|c|c|c|c|c|c|c|c|c|}
\hline Molecule & $6-31 G^{*}$ & $6-311 \mathrm{G}^{* *}$ & cc-pVDZ & cc-pVTZ & Molecule & $6-31 G^{*}$ & $6-311 \mathrm{G}^{* *}$ & cc-pVDZ & cc-pVTZ \\
\hline $\begin{array}{l}\mathbf{S}(\mathbf{N H})_{2} \\
(s, s)\end{array}$ & 0.0 & 0.0 & 0.0 & 0.0 & $\begin{array}{l}\mathrm{Se}(\mathbf{N H})_{2} \\
(s, s)\end{array}$ & 0.0 & 0.0 & 0.0 & 0.0 \\
\hline$(a, a)$ & 25.0 & 25.9 & 22.3 & 14.9 & $(a, a)$ & 20.7 & 21.7 & 23.6 & 15.7 \\
\hline$(s, a)$ & 4.7 & 5.2 & 4.1 & 1.5 & $(s, a)$ & 4.0 & 5.6 & 6.8 & 3.4 \\
\hline $\begin{array}{l}\text { S(NMe) } \\
(s, s)\end{array}$ & 5.8 & 4.7 & 10.9 & 9.4 & $\begin{array}{l}\mathbf{S e}(\mathbf{N M e})_{2} \\
(s, s)\end{array}$ & 8.5 & 6.1 & 6.9 & 8.5 \\
\hline$(a, a)$ & 30.5 & 34.5 & 30.3 & 25.6 & $(a, a)$ & 27.7 & 29.1 & 28.9 & 24.7 \\
\hline$(s, a)$ & 0.0 & 0.0 & 0.0 & 0.0 & $(s, a)$ & 0.0 & 0.0 & 0.0 & 0.0 \\
\hline $\begin{array}{l}\mathbf{S}\left(\mathbf{N}^{t} \mathbf{B u}\right)_{\mathbf{2}} \\
(s, s)\end{array}$ & 34.4 & 35.0 & 41.9 & 36.9 & $\begin{array}{l}\mathbf{S e}\left(\mathbf{N}^{\mathbf{t}} \mathbf{B u}\right)_{2} \\
(s, s)\end{array}$ & 40.2 & 23.1 & 24.9 & 24.8 \\
\hline$(a, a)$ & 24.4 & 27.6 & 24.2 & 19.4 & $(a, a)$ & 24.1 & 27.6 & 21.4 & 16.8 \\
\hline$(s, a)$ & 0.0 & 0.0 & 0.0 & 0.0 & $(s, a)$ & 0.0 & 0.0 & 0.0 & 0.0 \\
\hline $\begin{array}{l}\mathbf{S}\left(\mathbf{N S i M e}_{3}\right)_{2} \\
(s, s)\end{array}$ & 14.2 & 12.9 & 26.1 & 18.1 & $\begin{array}{l}\mathrm{Se}\left(\mathbf{N S i M e}_{3}\right)_{\mathbf{2}} \\
(s, s)\end{array}$ & 23.3 & 13.3 & 20.7 & 17.0 \\
\hline$(a, a)$ & 17.2 & 20.8 & 19.3 & 11.1 & $(a, a)$ & 15.5 & 15.1 & 16.7 & 10.6 \\
\hline$(s, a)$ & 0.0 & 0.0 & 0.0 & 0.0 & $(s, a)$ & 0.0 & 0.0 & 0.0 & 0.0 \\
\hline
\end{tabular}




\section{Figure Captions}

Figure 1. The syn,syn, syn, anti, and anti,anti conformations of chalcogen diimides $\mathrm{E}(\mathrm{NR})_{2}$.

Figure 2. The dependence of NEN and ENA bond angles $(E=S, S e ; A=H, C, S i)$ on the organic substituent $\mathrm{R}$ in (a) $\mathrm{S}(\mathrm{NR})_{2}$ and (b) $\mathrm{Se}(\mathrm{NR})_{2}$.

Figure 3. The RHF/6-31G*, MP2/6-31G*, and B3PW91/6-31G* relative energies of the different conformations of (a) $\mathrm{S}(\mathrm{NR})_{2}$ and (b) $\mathrm{Se}(\mathrm{NR})_{2}$.

Figure 4. The $\operatorname{CCSD}(\mathrm{T}) / \mathrm{cc}-\mathrm{pVDZ} / \mathrm{B} 3 \mathrm{PW} 91 / 6-31 \mathrm{G}^{*}$ relative energies of the different conformations of $\mathrm{S}(\mathrm{NR})_{2}$ and $\mathrm{Se}(\mathrm{NR})_{2}$. 


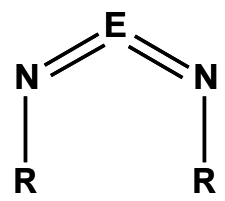

$(s, s)$

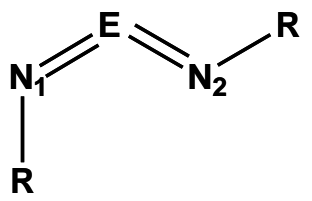

$(s, a)$<smiles>[R]N=[Fe]=N[R]</smiles>

$(a, a)$

Figure 1 
(a)
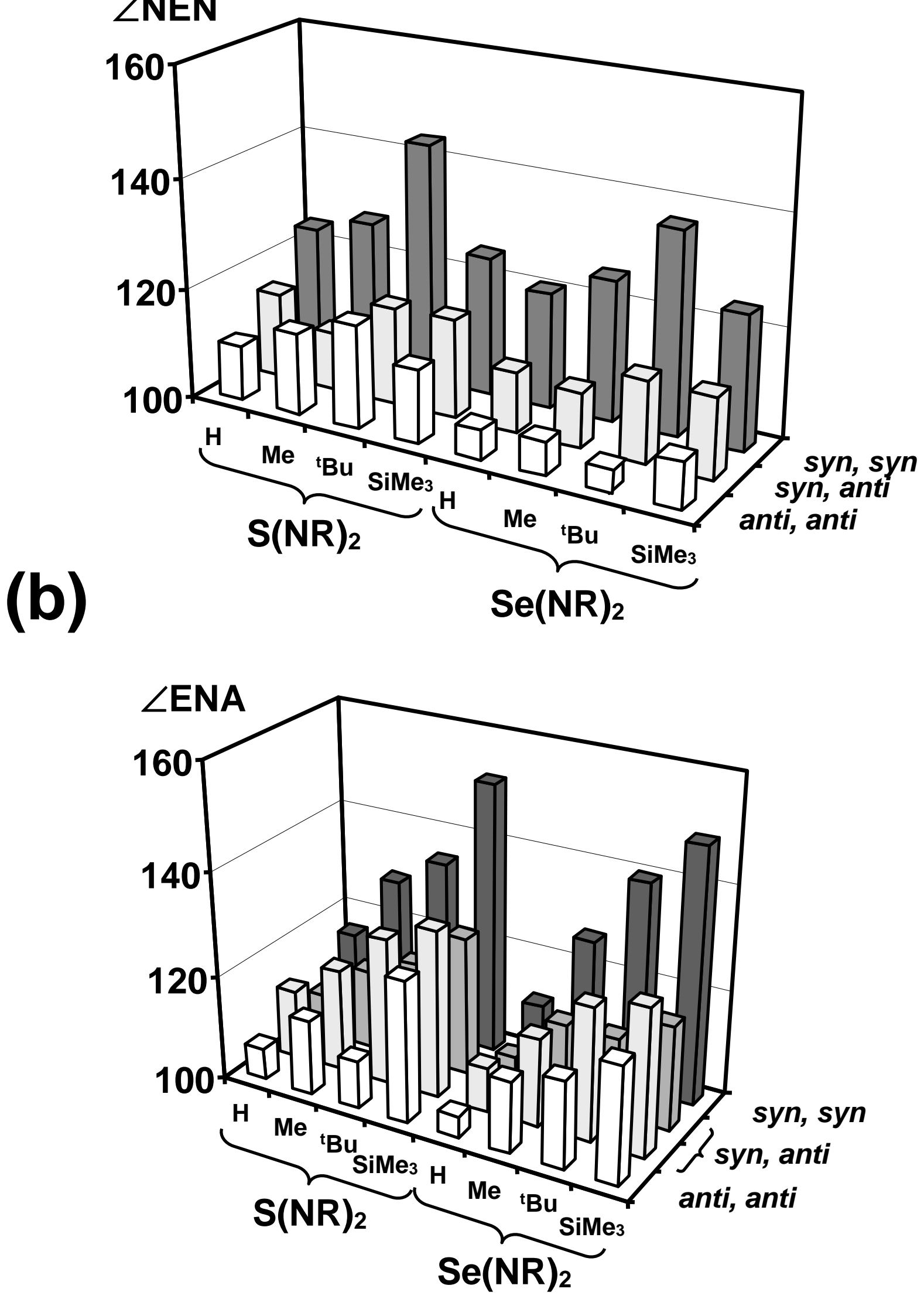

Figure 2 
(a)

\section{$\mathrm{kJ} \mathrm{mol}^{-1}$}

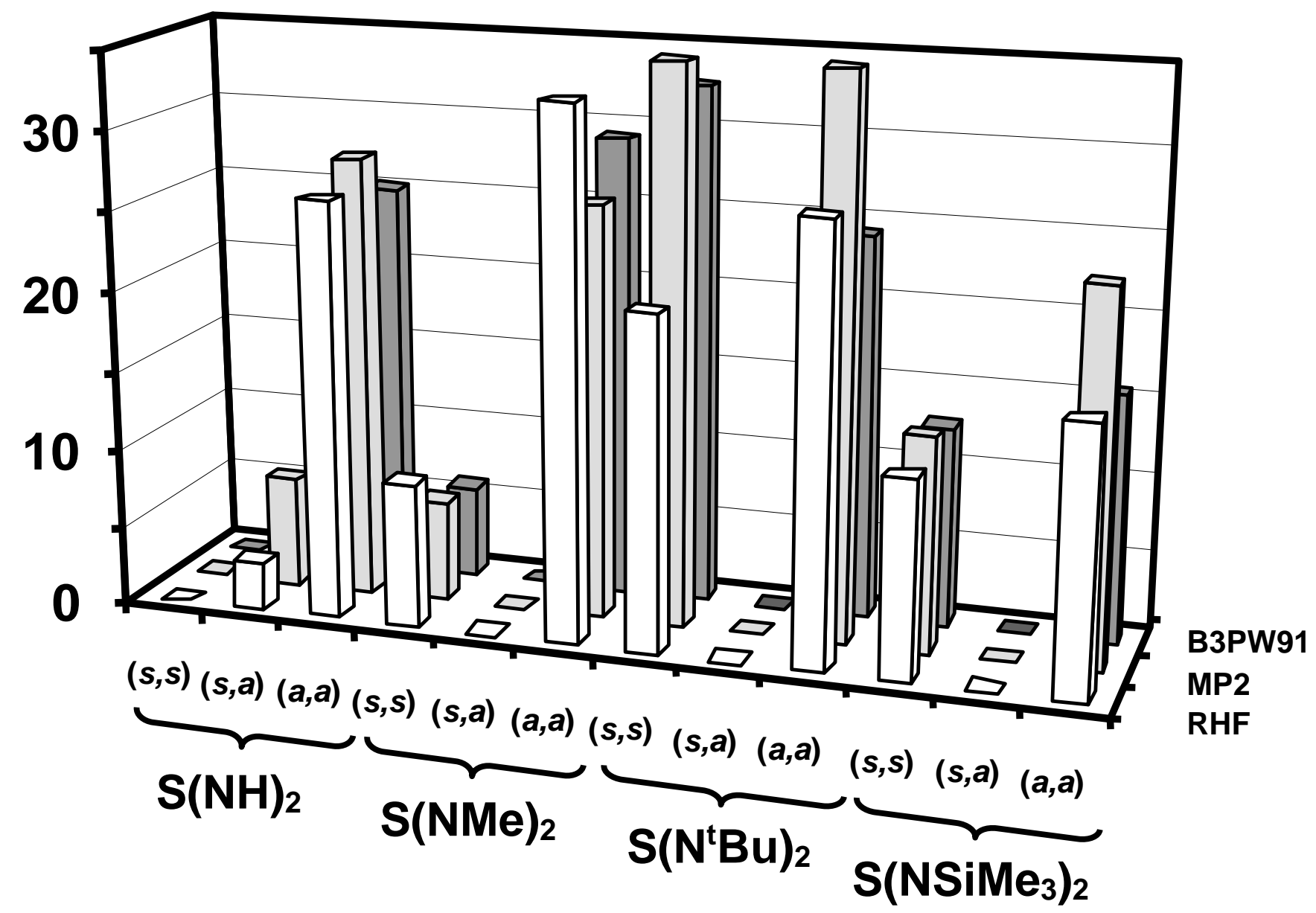

Figure 3(a) 
(b)

$\mathrm{kJ} \mathrm{mol}^{-1}$

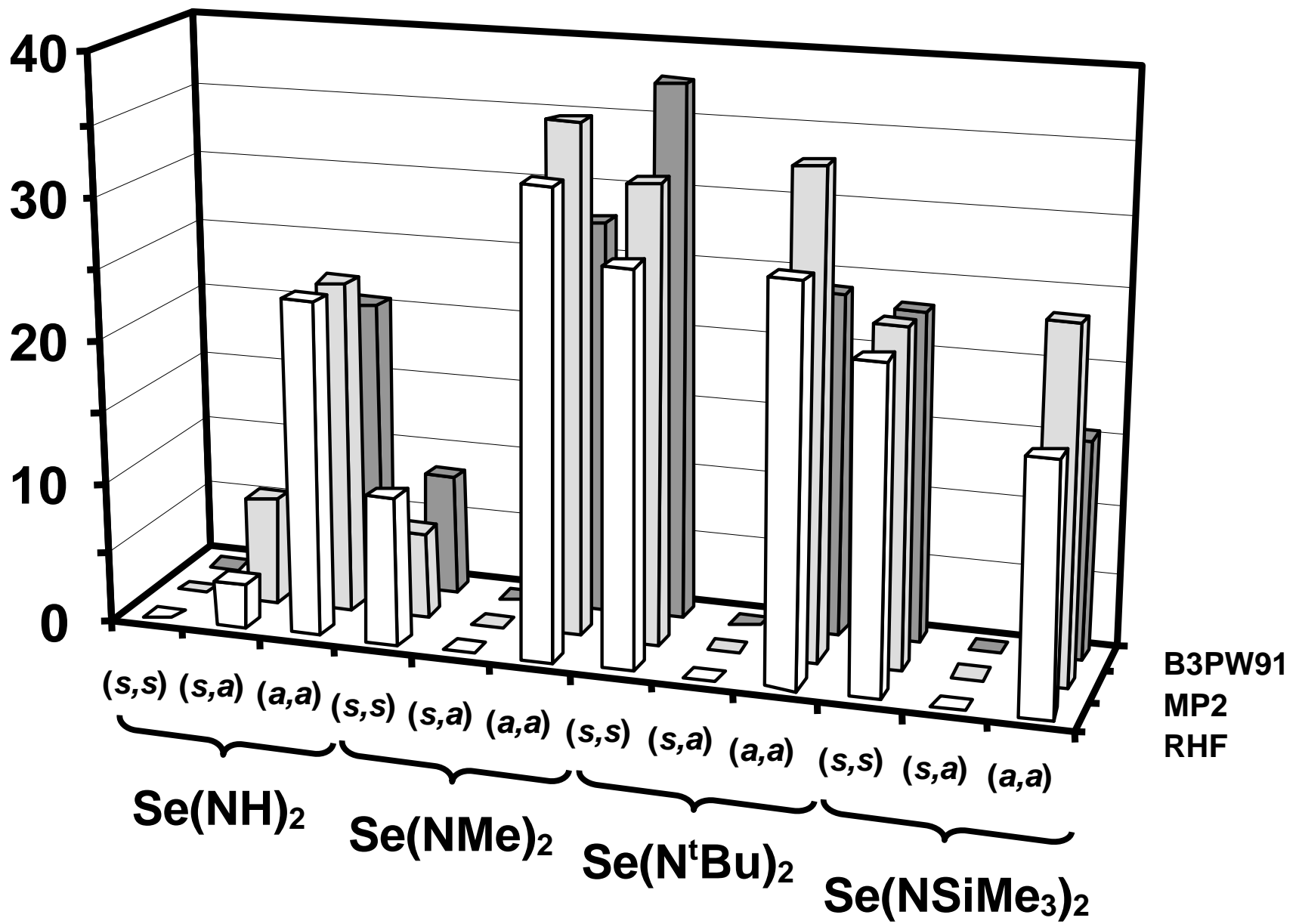

Figure 3(b) 


\section{$\mathrm{kJ} \mathrm{mol}^{-1}$}

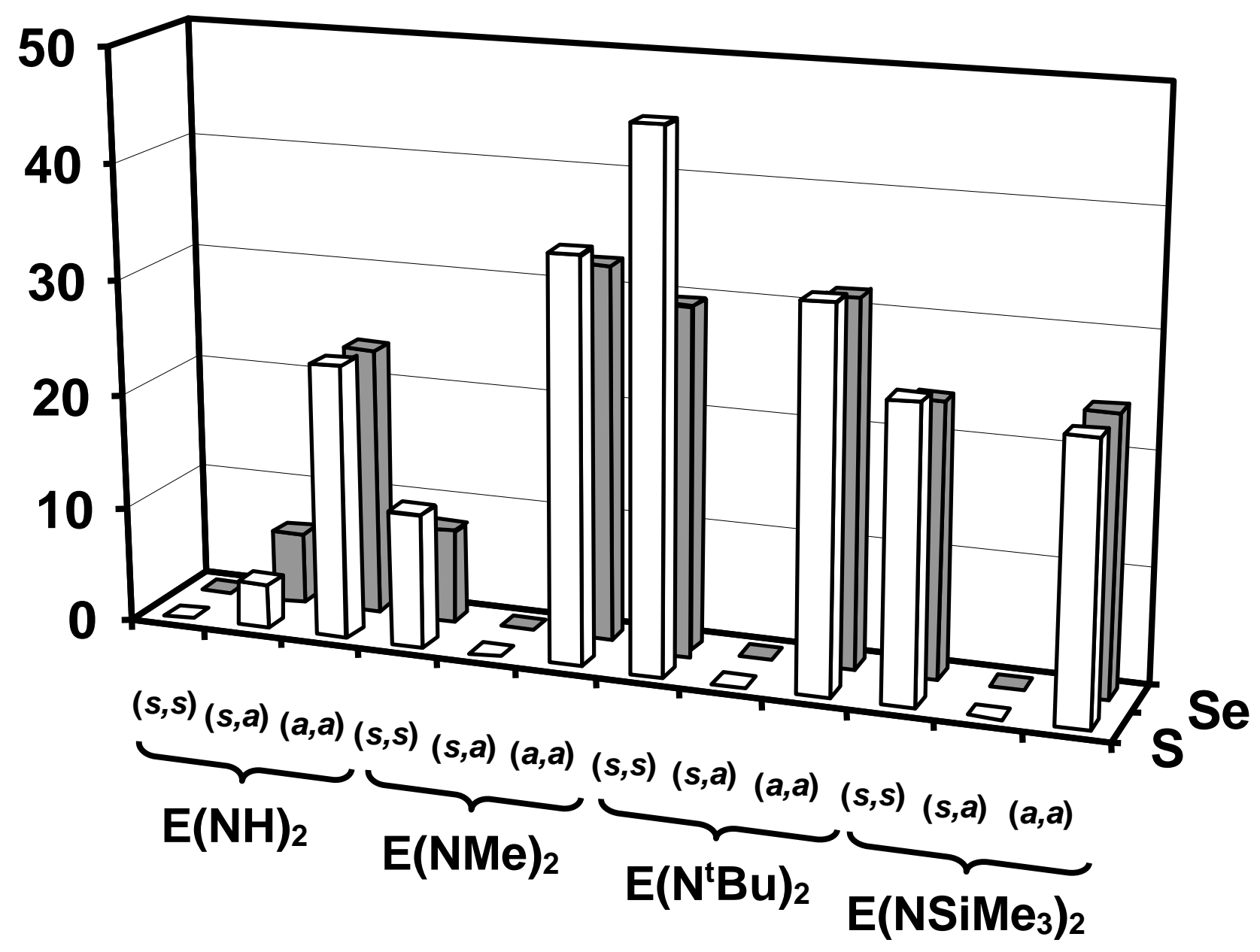

Figure 4 